\title{
A TUTORIA EM EAD E O PERFIL PROFISSIONAL DOS DOCENTES QUE BUSCAM CURSOS DE QUALIFICAÇÃO EM TUTORIA EAD PARA ATUAR NO AMBIENTE DE EDUCAÇÃO A DISTÂNCIA
}

\author{
SÃO PAULO/SP MAIO/2018
}

\begin{abstract}
Leonardo Manoel Mendes - UNIFACCAMP - leonardomanoelmendes@gmail.com
Elaine Barbosa de Figueiredo - UAM - ebfigueiredo@anhembi.br

Renan Aleixo Paganatto - UNIFFACCAMP - renan.ccn@gmail.com

Júlio Alberto Vansan Gonçalves - UNIFFACCAMP - julio@vansan.com.br

Eliana Pereira da Silva - UNIFFACCAMP - eliana.pereiras@gmail.com

Jairo Marciano Silva - UNIFFACCAMP - jairo.silva@prof.uscs.edu.br

Ricardo Resende de Mendonça - UNIFFACCAMP - ricardo.resende@gmail.com
\end{abstract}

\author{
Tipo: Investigação Científica (IC) \\ Natureza: Relatório Final de Pesquisa \\ Categoria: Pesquisa e Avaliação \\ Setor Educacional: EDUCAÇÃO MÉDIA E TECNOLÓGICA, EDUCAÇÃO SUPERIOR, \\ EDUCAÇÃO CONTINUADA EM GERAL
}

\begin{abstract}
RESUMO
Este artigo tem como objetivo mostrar o panorama da tutoria em cursos de educação a distância $E A D$, assim como uma análise do perfil dos profissionais de nível superior que buscam aperfeiçoamento para atuar na tutoria de curso disponíveis em ambientes de aprendizagem online na modalidade EAD. Com a análise do perfil dos alunos de tutoria disponíveis na plataforma foi possível identificar que existem uma gama de profissionais atuando em diferentes níveis da docência e, atualmente estão buscando aprimoramento profissional para atender a essa nova demanda com uma legião de cursos que são criados e ofertados em ambientes online, fazendo uso dos recursos de ferramentas de tecnologias da informação e comunicação.

Para suprir as necessidades das faculdades e universidades com os cursos online, surge a necessidade de um profissional "Tutor" para auxiliar os alunos durante a sua trajetória no curso. Dessa forma, o tutor assume um papel fundamental para que os alunos de cursos na modalidade de EAD possam reportar suas dificuldades bem como as necessidades nas plataformas desenvolvidas para 0 funcionamento de cada curso.
\end{abstract}

Palavras-chave: educação a distância, tutoria, formação de tutores, papel do tutor em EAD.

\section{AGRADECIMENTOS}

APRADEÇEMOS A TODOS QUE PARTICIPARAM DE FORMA DIRETA E INDIRETA QUE DISPONIBILIZARAM SEUS DADOS NO PERFIL DO CURSO DE TUTORIA EM EAD. AOS COLEGAS QUE PARTICIPARAM DA ESCRITA DO ARTIGO, E ORIENTADORES. 


\section{Introdução}

No contexto da educação a distância, o tutor desempenha um papel de grande importância, podendo ser considerado um fator de sucesso ou insucesso durante a tutoria em uma disciplina ou módulo de um curso. A presença do tutor pode ser encontrada em diferentes modalidades de ensino, sendo elas: Presencial, Semipresencial e Educação a Distância, esta última conhecida como EAD. Para este trabalho será adotada a tutoria em ambiente EAD. Com o crescimento e expansão da rede faculdades e universidades públicas e particulares no Brasil, surgem novas modalidades de ensino, tais como o ensino semipresencial e EAD, isso em diferentes níveis de formação e qualificação profissional e, com esta expansão surge a figura doTutor funciona como um orientador dando apoio técnico para que o aluno possa se sentir confortável no Ambiente Virtual de Aprendizagem - AVA durante a realização das atividades do curso, tais como: discussão nos fóruns, realização de atividades em grupo por meio de wikis, dentre outras ferramentas para compartilhamento de dúvidas e colaboração em equipes.

Atualmente, percebe-se que, para atuar como tutor é necessário não só o conhecimento da área de formação de cada um, mas possuir conhecimentos e práticas na utilização dos recursos de tecnologias da informação e comunicação - TIC's, para que o tutor possa auxiliar os alunos na plataforma adotada para a realização do curso e, baseado neste contexto, cada vez mais profissionais com diferentes níveis de formação acadêmica, ou seja, Graduação, Pós-Graduação Lato Sensu, Mestrado e Doutorado buscam aperfeiçoamento na tutoria em EAD para que possam atuar em diferentes modalidades de ensino ofertados pelas faculdades e universidades de diversas naturezas.

Com o intuito de mostrar um panorama do perfil de profissionais da docência que buscam aprimoramento na tutoria em EAD, buscou-se analisar os perfis de 35 alunos de um curso de tutoria em EAD. A coleta de dados foi realizada por meio das descrições textuais existentes em cada um dos perfis dos alunos na plataforma em que o curso foi ofertado, a coleta gerou dados qualitativos e quantitativos como demonstram os respectivos resultados do presente estudo.

\section{Tutoria em EAD}

Nas últimas décadas os avanços de tecnologia de informação e comunicação TIC, têm proporcionado grandes revoluções em diversas áreas de conhecimento e, na área da educação as TIC's proporcionam acesso ao conhecimento além das barreiras físicas da 
educação tradicional e presencial, baseado neste contexto, a modalidade de ensino em ambientes online possui características próprias e não pode perder de vista a finalidade última dos espaços educacionais, presenciais ou virtuais, o desenvolvimento dos sujeitos e suas aprendizagens. (OLIVEIRA \& CRUZ, 2011). A tutoria em EAD é uma atividade de grande importância para que os cursos desenvolvidos em ambiente web possam ser desenvolvidos com qualidade. De acordo com (Brasileiro, 2017), os modelos de EAD mais praticados no Brasil, existem duas figuras principais para auxiliar os alunos no alcance dos objetivos na aprendizagem, sendo eles, o professor e o tutor. Para as autoras tanto o professor quanto o tutor com funções próprias e interdependentes. Estes profissionais da educação estão inseridos em um contexto mais amplo e envolve profissionais de diferentes áreas de atuação.

De acordo com (Schlosser, 2010), a modalidade de EAD estabelece uma mudança na relação existente entre professor e seus alunos, ou seja, não existindo a necessidade de se ter uma relação face a face entre professor e aluno e foram dos limites físicos impostos pela educação presencial. Neste sentido, a modalidade EAD permite ao aluno um autogerenciamento para que possa assistir as aulas e realizar suas respectivas atividades. Em seu artigo, (L. P. Ferreira, 2012) aponta que na EAD um desafio para o tutor ou professor não possui informações visuais ou mesmo verbais do aluno.

\section{O papel do tutor em ambiente EAD}

O avanço dos recursos tecnológicos no século XXI proporcionaram grandes revoluções em diferentes áreas de conhecimentos e, na área da educação um dos ganhos foi a EAD por meio dos recursos da internet com o desenvolvimento de Ambientes Virtuais de Aprendizagens - AVA e, para (Bernardino, 2011) a Educação a Distância se apresenta no século XXI como um novo espaço de trabalho educacional, trazendo mudanças nos papéis tradicionais, requerendo um preparo especial do tutor, que é uma "ferramenta" essencial neste processo. Para (Gusso, 2009), o tutor deve orientar, promover, propõe, integra, incentiva, acompanha e avalia. Para que o tutor possa desempenhar todas estas atividades em um ambiente de aprendizagem em um curso EAD é necessário esteja capacitado para desempenhar tais funções. A tutoria em EaD no cenário atual exige que o tutor busque aperfeiçoamento profissional e atualização nos recursos tecnológicos para que o mesmo possa auxiliar os alunos por meio de ferramentas de softwares e mídias digitais utilizadas nos ambientes dos cursos ofertados na modalidade EAD. De acordo com (Martins, 2003), a educação a distância mediada por computador revela-se, a cada dia, uma perspectiva de crescimento das práticas profissionais. Baseado na visão da autora, a educação mediada por computador proporciona ao Tutor aperfeiçoamento na área. 
A EaD é de grande importância para a formação em larga escala de profissionais em diferentes áreas do conhecimento, no entanto, este tipo de formação exige um conjunto de fatores que são determinantes para o sucesso durante a realização do curso. Dentre os fatores existentes, o tutor possui um papel de extrema importância, uma vez que, em um curso de formação na modalidade EAD, existe uma série de entraves e, o tutor por sua vez tem a função de auxiliar os alunos durante a sua jornada no curso. O ambiente de formação em EAD possui características específicas do ambiente o que o diferencia do método tradicional de uma sala de aula. $O$ ambiente de EAD requer do aluno um autogerenciamento das suas atividades e responsabilidades na execução das mesmas, na maioria dos casos, todo o contato existente entre alunos e professores ou tutores darse-ão por meio de fóruns, Wikis, etc. Para que possíveis dúvidas dos alunos referentes ao ambiente de aprendizagem ou módulo específico do curso possa ser esclarecida, os alunos, assim como os tutores, fazem uso de ferramentas de Tecnologias de informação e comunicação TIC's para que as interações entre alunos e tutores possam acontecer. Para (R. L. R. Ferreira, 2014), a EAD surge como uma possibilidade de vir a ser uma modalidade de educação inclusiva, mas, para isso é necessário mais que tecnologia. Para a autora as instituições devem auxiliar os alunos no uso dos recursos de tecnologia de comunicação e informação para que possam se tornarem autônomos na utilização de tais recursos. Esta contextualização reforça todo o embasamento afirmado por (Martins, 2003), onde afirma que a relação pedagógica presente na EAD é diversa, se fundamenta na pedagogia diferenciada, e o papel de tutor é fazer com que nasça no aluno o desejo de aprender.

De acordo com (Litto, 2014), na educação EAD há um grande número de principiantes que não possuem motivação, autonomia e disciplina para que possam se manter focados em um curso de nível universitário na modalidade de EAD. Ainda de acordo com o autor, os alunos sentem a necessidade de um professor para elogiar os seus feitos nos cursos, cobranças nas atividades. Baseado neste contexto, é possível identificar que grande parte dos alunos que frequentam os cursos na modalidade EAD não possuem maturidade para se manter no curso sem o auxilio de um tutor ou professor. Para (Martins, 2003), o tutor precisa tornar-se, por conta própria, um pesquisador em ação. Nesta visão, o tutor necessita buscar aperfeiçoamento profissional para que possa atuar na tutoria fazendo uso de todos os recursos disponíveis nos ambientes virtuais de aprendizagem. Ser um pesquisador em ação, faz com que o tutor passe a ser um agente produtor e disseminador de conhecimentos da sua própria pesquisa. Para (Silveira, 2005), não há como desenvolver um papel flexível, no entanto, a autora também afirma que não existem respostas prontas ou acabadas e que educar em qualquer que seja a modalidade é um movimento em formação do aluno que almeja a ação educativa. 


\section{Metodologia}

A metodologia adotada para o desenvolvimento deste estudo teve como objetivo a investigação exploratória e bibliográfica para ressaltar a importância e o papel dos tutores na EAD. Durante a coleta de dados, ou seja, os artigos que deram embasamento teórico para o presente trabalho, destacamos publicações existentes no portal de periódico da CAPES, Google Scholar com publicações referentes a abordagem do papel da tutoria na EAD e um portal de Formação de Tutoria em EAD.

Baseado na contextualização das publicações existentes e analisando o contexto no cenário nacional é possível identificar que a tutoria em EAD desempenha um papel de grande importância em diferentes níveis de formação, sendo eles, aperfeiçoamento profissional, cursos de extensões, cursos técnicos e tecnológico, graduação e pósgraduação em nível de Lato Sensu. Em cada um destes níveis de formação, o tutor é um recurso que tem a finalidade de auxiliar o aluno durante a sua trajetória no curso.

\section{Coleta de Dados}

A coleta de dados para o presente estudo foi realizada por meio da análise dos perfis dos alunos disponíveis na plataforma do curso. O curso foi realizado com o Ambiente Virtual de Aprendizagem - AVA, na Plataforma Moodle por uma Instituição de Ensino Superior Federal. Foram coletados dados quantitativos e qualitativos que geraram os resultados a serem descritos nas seções a seguir.

\section{A TUTORIA em EAD de acordo com os tutores em formação}

Durante a realização da análise dos perfis dos alunos de tutoria em educação à distância EAD, alguns depoimentos postados na plataforma pelos alunos. Os nomes verdadeiros dos participantes foram omitidos por questões éticas e preservação da identidade de cada um.

Tutor A: "A tutoria me possibilitaria ter experiência como docente de ensino superior paralelamente ao meu trabalho, além do que em minha região, como em todo Brasil tem crescido a oferta de cursos superiores no modelo EAD. Sendo assim vejo uma excelente oportunidade de mercado crescente e que me realizaria como docente de ensino superior contribuindo assim para o crescimento e a qualidade da educação no Brasil."

Tutor B: "Acredito na EAD como forma de aprimoramento e democratização do saber em diversas esferas do ensino (acadêmico, corporativo, etc.). A EAD aumentou a 
possibilidade de acesso à aprendizagem, flexibilizou os horários de estudo, possibilitou a redução de custos relacionados ao deslocamento, entre outras vantagens."

Tutor C: "Busquei o curso de capacitação à monitoria em EAD por ser para mim uma oportunidade de aprendizagem e desenvolvimento profissional. [...] espero, assim, ter oportunidade de conhecer colegas e professores, trocar experiências e, quem sabe, formar parcerias."

Tutor D: "Tenho atuado como Tutora a Distância do curso de Pedagogia de universidade estadual e me identificado muito com a Educação a Distância. Acho muito gratificante atuar em prol do acesso de muitos ao Ensino Superior e poder fazer parte da trajetória dessas pessoas com as quais aprendo tanto! Por isso, tenho ótimas expectativas em relação a este curso e espero aprimorar bastante minha prática na mediação."

Tutor E:"Meu interesse pelo curso de Tutoria de EAD é para dar minha contribuição para um ensino de qualidade e me capacitar profissionalmente, no que, sem dúvida, é a modalidade do presente e que a cada dia ganha mais importância na Educação Brasileira."

Tutor F: "A minha expectativa com o curso de extensão de Tutoria em EAD: Teorias e Práticas é fechar algumas lacunas que ainda possam estar abertas com relação ao ensino a distância e poder colaborar de forma melhor para com os meus objetivos, que, sem dúvida, é passar o que eu aprendi durante a jornada na área de Tecnologia da Informação."

Tutor G: "Como constantemente busco me atualizar, pretendo com o curso de TUTORIA EM EAD ganhar mais conhecimentos na área de educação a distância e trocar experiências com os participantes do curso."

Tutor H: "“Quero estar preparada para facilitar o aprendizado como tutora. Também venho acompanhando o crescimento desta modalidade de aprendizagem e acredito nela como meio de democratização da educação."

\section{ANÁLISE E RESULTADOS}

A análise teve como finalidade a coleta de dados dos perfis de cursistas da formação em tutoria em EAD, no entanto, foram coletados dados de 35 alunos de tutoria em EAD. A amostra resultou nos seguintes dados: gênero, grau de instrução e área de atuação 
acadêmica. Dos 35 alunos de Tutoria em EAD, 18 participantes do gênero masculino, 17 do gênero feminino. A analise resultou em dados da formação, ou seja, grau de instrução de cada participante e suas respectivas áreas de atuação acadêmica.

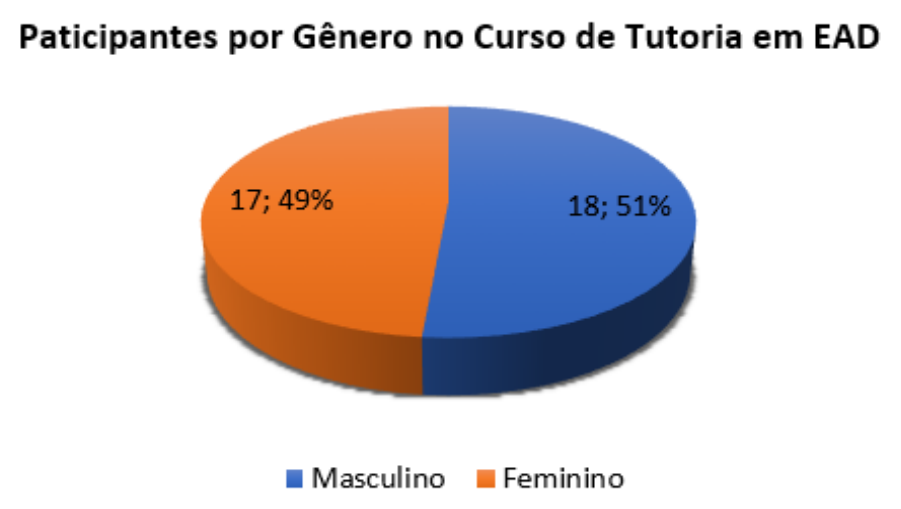

Figura 1. Percentual dos participantes por gênero

Baseado na análise dos perfis dos participantes do curso de tutoria em EAD, foi identificado que, o maior número de participante foi do gênero masculino com 18 participantes, sendo que este número corresponde a $51 \%$ do total. Enquanto participantes do gênero feminino foram 17, sendo que este número corresponde a $49 \%$ do total de participantes. Estes dados são dos alunos que iniciaram o curso e cumpriram todas as etapas da formação na Tutoria em EAD. Estes dados ressaltam a importância do curso de tutoria na formação do Tutor em EAD, tendo em vista que, a cada dia as faculdades e universidades criam cursos nesta modalidade de ensino em diferentes níveis de formação, ou seja, cursos técnicos, tecnológicos, graduação, extensões e cursos de pós-graduação Lato Sensu no formato da EAD com auxílio dos recursos de Tecnologias da Informação e Comunicação TIC's. A pesquisa também teve como objetivo coletar dados do grau de instrução dos alunos do curso de Tutoria em EAD.

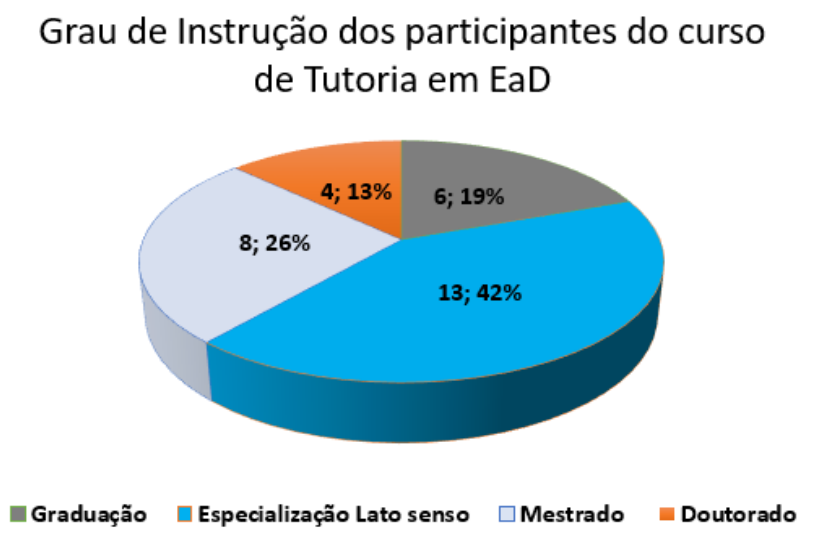

Figura 2. Grau de Instrução dos participantes do curso de Tutoria em EAD 
Após a análise dos dados foi identificado que dentre os 35, apenas 29 participantes forneceram o seu grau de instrução. Diferente os 29 perfis analisados, foram identificados que 6 participantes possuíam apenas o nível de Graduação, esse total 6 corresponde a $19 \%$ do total de participantes. Nos dados disponíveis não tínhamos a informação se a graduação dos participantes era licenciatura ou bacharelado, apenas constava o nome do curso. No entanto, a pós-graduação lato senso foi o nível com maior número de participantes, sendo 13 que corresponde a $42 \%$ do total. Para os participantes com grau de mestre foram identificados 8 participantes que corresponde a $26 \%$. Para os participantes com grau de doutor foram identificados 4 alunos, estes correspondem a $13 \%$ do total.

Com base na análise de perfis de alunos de Tutoria em EAD é possível concluir que indiferente no grau de instrução, os profissionais que atuam na área da docência estão buscando atualizações para que possam se aperfeiçoar na tutoria em EAD e dessa forma poder auxiliar os alunos nos Ambientes Virtuais de Aprendizagem - AVA, em diferentes áreas de conhecimentos.Os graduados, especialistas, mestres e doutores, estão atuando em diferentes áreas de conhecimentos, tais como: ciências humanas, ciências exatas, ciências da natureza, biológicas e da saúde. A figura 3 retrata o cenário da área de atuação dos perfis dos Tutores em formação.

\section{Áreas de Atuação profissional dos participantes do Curso} de Tutoria em EaD

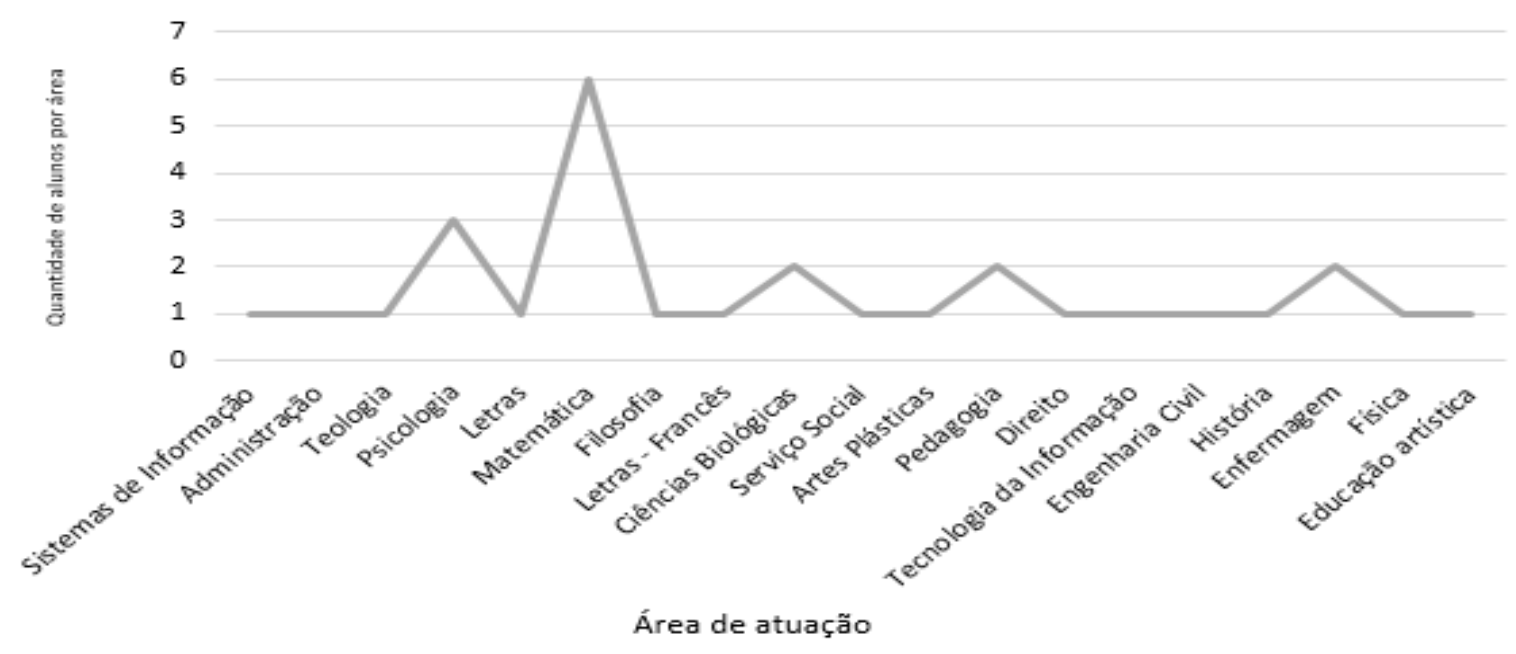

Figura 3. Área de Atuação dos participantes do Curso de Tutoria em EAD

Com base na figura 3 é possível concluir que há uma diversidade de profissionais que atuam na docência e buscam aperfeiçoamento profissional para que possam atuar na modalidade de EAD. Como visto na figura 3, as áreas de formação dos participantes correspondem a 19 áreas, sendo elas: Sistemas de Informação 1 participante que 
corresponde a 3\%, Administração 1 participante que corresponde a 3\%, Teologia 1 participante que corresponde a $3 \%$, Psicologia 3 participantes que corresponde a $10 \%$, Letras 1 participante que corresponde a 3\%, Letras com habilitação em Francês 1 participante que corresponde a $3 \%$, Matemática 6 participantes que corresponde a $21 \%$, Filosofia 1 participante que corresponde a 3\%, Ciências Biológicas 2 participantes que corresponde a $7 \%$, Serviço Social 1 participante que corresponde a $3 \%$, Artes Plásticas 1 participante que corresponde a 3\%, Pedagogia 2 participantes que corresponde a $7 \%$, Direito 1 participante que corresponde a 3\%, Tecnologia da Informação 1 participante que corresponde a 3\%, Engenharia Civil 1 participante que corresponde a 3\%, História 1 participante que corresponde a $3 \%$, Enfermagem 2 participante que corresponde a $7 \%$, Física 1 participante que corresponde a 3\%, e Educação Física 1 participante que corresponde a $3 \%$.

Como visto, há uma gama de perfis profissionais que atuam na docência e com tutorias em busca de conhecimentos e nas práticas da Tutoria em EAD para que possa desempenhar o seu papel no exercício na formação em educação a distância em diferentes níveis de formação nas faculdades e universidades com cursos EAD.

\section{CONCLUSÃO}

O presente trabalho nos mostrou a importância que educação à distância tem na atualidade, assim como os profissionais envolvidos no contexto desta modalidade de ensino. Em especial, a figura do Tutor que tem por finalidade ser um interlocutor entre 0 aluno e a equipe de professores e técnicos que compõe a equipe para o bom funcionamento da plataforma de ensino em EAD. Como visto, a tutoria em EAD vem despertando o interesse de profissionais docentes da graduação ao doutorado em diferentes áreas de conhecimentos. Perfis bem heterogêneos, não existindo uma única área de formação, a tutoria em si, busca ofertar igualdade de oportunidade de conhecimento no ambiente virtual de aprendizagem para que todos possam usufruir dos conteúdos e participação nas temáticas abordadas em cada módulo de um determinado curso em EAD, isso por meio da utilização dos recursos de tecnologias de informação e comunicação TIC's como são conhecidas para que cada um cumpra com o seu papel no ambiente de aprendizagem, seja tutor ou aluno.

\section{REFERÊNCIAS}

BERNARDINO, H. S. (2011). A tutoria na Ead: Os Papéis, as competências e a relevância oo tutor. Revista Científica de Educação À Distância, 2(4). 
BRASILEIRO, A. A. (2017). Curso de Extensão Tutoria: Teoria e Prática LANTE-UFF.

FERREIRA, L. P. (2012). Avaliação no Ensino a Distância: Possibilidades e Desafios. Simpósio Internacional de Educação a Distância - EnPED - Encontro de Pesquisadores Em Educação a Distância, 2012. São Carlos, 1-6.

FERREIRA, R. L. R. (2014). Utilização De Ambientes Virtuais De Ensino E Aprendizagem Com Tecnologia 3D Em Educação a Distância. $20^{\circ}$ Congresso Internacional de Educação a Distância- Anais, 1-10. Retrieved from http://www.abed.org.br/hotsite/20-ciaed/pt/anais/pdf/65.pdf

GUSSO, S. de F. K. (2009). O TUTOR - PROFESSOR E A AVALIAÇÃO DA APRENDIZAGEM NO ENSINO A DISTÂNCIA Sandra de Fátima Krüger Gusso i. Ensaios Pedagógicos: Revista Eletrônica Do Curso de Pedagogia Das Faculdades OPET - ISSN 2175 1773, 53-68.

LITTO, F. M. (2014). As interfaces da EAD na educação brasileira. Revista USP, $O(100)$, 57. https://doi.org/10.11606/issn.2316-9036.v0i100p57-66

MARTINS, O. B. (2003). Teoria e prática tutorial em educação a distância Distance education 's tutoring practice and theory, 153-171.

OLIVEIRA, V. do C., \& Cruz, F. M. L. (2011). A avaliação da aprendizagem na educação a distância : um estudo sobre as concepções docentes na ead online. $3^{\circ}$ Simpósio Hipertexto E Tecnologias Na Educação, 1-27.

SCHLOSSER, R. L. (2010). A atuação de tutores nos cursos de Educação a Distância. Revista Digital Da CVA - Ricesu, 6(22), 1-11.

SILVEIRA, R. B. L. Da. (2005). A Importância Do Tutor No Processo De Aprendizagem a Distancia. Revista Iberoamericana de Educación, 1-6. Retrieved from http://dialnet.unirio ja.es/servlet/dcart?info=link\&amp;codigo=3158803\&amp;orden=241205 